\title{
Investigating sexuality education in South African schools: A matter of space, place and culture
}

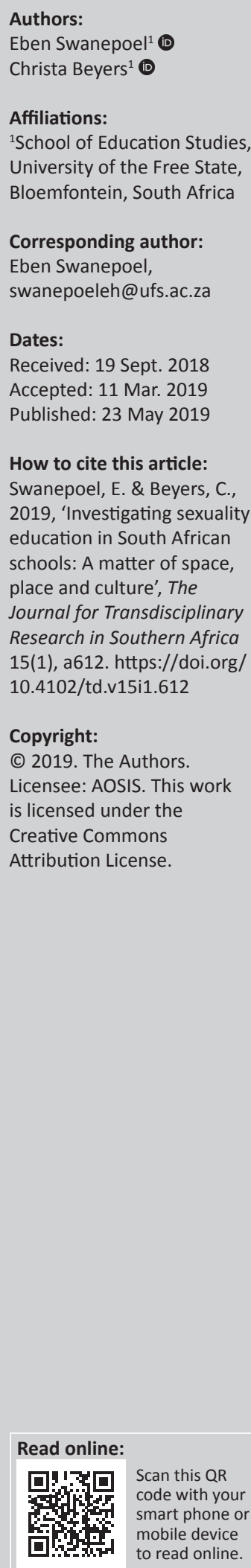

\begin{abstract}
Sexuality education has faced various challenges in being successfully implemented within secondary schools in South Africa. Research points towards barriers thereto, which include teacher bias and limited knowledge as core mediators to socially-just education. Research in the subject of Life Orientation, specifically the theme of sexuality education, has largely focused on teacher responses and challenges within the teaching of sexuality. Scant research, however, exists on how schools as a systemic whole manifest and sustain sexuality education. This research article is guided by the primary question: how do schools, from a systemic level, mediate sexuality education in relation to space, place and culture? As such, the research reported in this article encompasses a systemic approach to understand how sexuality education is maintained within schools. Through purposive sampling, 12 participants from 6 schools in the Free State province were chosen to take part in semi-structured interviews. The sample of participants comprised Life Orientation teachers and school principals and co-managerial staff. Through the framework of cybernetics, it was found that schools face different challenges in relation to their geographical place, as well as the space within which they reside socio-economically. Core themes that emerged from the data include curriculum boundaries and teacher knowledge. We further found that culture influences how sexuality education manifests within a specific context.
\end{abstract}

Keywords: Cybernetics; sexuality education; spaces; place; social justice.

\section{Introduction}

South African culture has become increasingly complex, with multicultural norms and indigenous knowledge systems having to abide by a uniform benchmark of constitutional rights based on inclusivity and acceptance of diversity (The Bill of Rights 1996). This plurality of culture implicates teaching practices as many educational spaces are faced with the need to transfer knowledge flexible to societal norms and values (Weeks 2012). This need for the flexibility of adaptable knowledge to the 21st century paradigm to shift from static knowledge is further intensified by globalisation (Jonck \& Swanepoel 2015). This requires a multicultural space where knowledge is mediated, which is not only curriculum and policy-based standardisation, but also culturally acceptable across the spectrum of culturally diverse learners characteristic of South African educational spaces (Swanepoel \& Beyers 2015). The classroom is thus highly underpinned by South Africa's sociopolitical context, and this complicates the manner in which content is taught, as knowledge should, ideally, be dynamic and continuously re-constructed in such a rapid manner that educators need to constantly re-imagine the space and place within which their pedagogical practice takes place (DePalma \& Fancis 2014).

The topic of sexuality within school spaces has become the main focus in recent South African research and is, in conjunction with cultural purity, an equally difficult concept to dynamically construct and act upon within the classroom setting. In a further effort to curb issues related to unsafe sexual practices, schools have become the cornerstone in implementing programmes to readdress past injustices which still remain rife at present. Post-apartheid South Africa is still troubled with racial and sexual inequalities, implicating the manner in which educators adapt and tailor pedagogies to fit the needs of learners, not only within classrooms but also to mediate teachings to the relevance of learners' sociopolitical backgrounds (Department of Basic Education 2011; Msibi 2012). Schools have thus become key spaces within which the construction of identities can emerge and be constructed (Woolley 2017). However, South African school spaces have not shown the desired influence in creating and shaping learner identities, but rather often still dictate rules and boundaries related to sex and gender, which are obstacles to the ideals of social justice and inclusivity (Swanepoel, Beyers \& De Wet 2017). 
There has, however, been a global shift in creating curriculum spaces that are indicative of inclusivity of gender and sexuality (Haberland \& Rogow 2015). While school spaces may also be better aligned with policies and mission statements of inclusivity, teachers face ongoing challenges in aligning teaching to critically engage and intervene in issues related to sexuality (Vavrus 2009). As core facilitators to programmes implemented at educational levels, teachers are increasingly being positioned in spaces of negotiating pedagogies, which align with the ideals of comprehensive and socially-just education (Ahmed et al. 2009) as a means to establish past inequalities and instill values of inclusivity and acceptance within places of learning.

\section{Schools as spaces and places of culture and sexuality}

Fields and Payne (2016) draw on 'place' as the material construct of the school itself, in a tangible respect of visibility. It is within certain places, such as schools, that meaning is constructed by learners and their actions; thus, 'schools become schooling' and ultimately become 'actions' rather than just a place within a certain location. In conjunction with the need to curb risks of unsafe sexual practices, it is important to acknowledge the importance of changing core values and destructive gender norms within classroom spaces (Cobbett-Ondiek 2016), and thus not to place sole focus on changing places as prime focuses of intervention. A contextual approach to such an understanding is needed as teaching about sex and sexuality is not limited to the classroom as a place of learning, but also towards the outside place of the school setting and community as a whole (Haberland \& Rogow 52015; Mthatyana \& Vincent 2015 Thus,). Thus, DePalma and Francis (2014) argue the need for intercultural dialogues to enter school spaces as a means to establish critical sexuality education that engages multiple levels of the learners' contexts and consequently a multistakeholder approach thereto.

However, school spaces often neutralise gender and sexuality, desexualising learners, and in turn create perceptions of retaining learner innocence through silencing the topic of sex and sexuality (Shefer \& Ngabaza 2015). Vavrus (2009) reflects on the argument that school spaces are dictated by social norms, which is to the disadvantage of teaching the content aimed at national policy benchmarks. Sociological order and normative discourses have established the dichotomy of 'male' and 'female' as the culturally accepted norm by which masculinity and femininity are compared, learnt and subsequently acted upon (DePalma 2013).

Educational spaces are salient spaces of socialised gender expectations and gender-specific triggers. This is visible in the division of single-sex-based schools and mixed-gender schools (Swanepoel \& Beyers 2015), each carrying specific challenges and norms by which school ethos is realised. Gender and sexuality serve as strong regulators of how power manifests and is exerted within educational spaces (Carrera, DePalma \& Lameiras 2012), especially at secondary schooling level, with the onset of adolescent puberty and sexual exploration and experimentation. However, sexuality and gender already manifest as strong socialised structures in primary school spaces, which are often overlooked and mistakenly classified as spaces where sex and gender evade the need for teaching, mistakenly classifying primary schools a zones of sexual comfort, innocence and adult-based exclusivity of knowledge (DePalma \& Janette 2010).

Drawing extensively on the emotional underpinning of teacher discomfort, Reygan and Francis (2015) refer to heteronormative attitudes within which sexuality pedagogies are situated. Francis (2016) further echoes the work of Beyers (2013) in the discomfort of teachers in responding to, or acknowledging, these relations of hegemonic control in the classroom by either complete silence surrounding sexuality or by playing it 'safe' as a means to eliminate emotional triggers and stay within safe socially accepted spaces of gender and sexuality when teaching about what is healthy sexual behaviour (Beyers 2013). It is clear that, whether explicitly or implicitly, teachers approach sexuality, frustration and fear with messages which often manifest situational knowledge within spaces that promote the marginalisation of sexuality and gender.

\section{Research aim and questions}

There is an urgent need to gain understanding as to how educators utilise schools and classrooms as spaces of social change during sexuality education (Cobbett-Ondiek 2016). This study aims to understand how schools within the same contextual space of the Free State province manifest and mediate sexuality education. As schools are contextually different, it is understandable that there will be contextual factors which differentiate different schools in their approach to sexuality education. The main question guiding this study is thus: how do schools, at a systemic level, mediate sexuality education in relation to space, place and culture?

\section{Theoretical framework: First- and second-order cybernetics}

The underpinning for this article's theoretical framework arises from the work of systemic thinking, more specifically cybernetics from a first- and second-order perspective. Banathy and Jenlink (2003) draw on cybernetics in the selfregulator manner in which systems manifest and sustain order at structural level. More specifically, systems are continuously influenced by feedback processes and the manner in which systems subsequently respond thereto and regulate themselves as a means to maintain structural integrity and homeostasis. At first-order level, emphasis is not on the meaning of such feedback, or noise, and subjectivity thereto is thus not relevant. Focus is placed on the 'what' counterpart of how systemic structure is maintained, as opposed to 'why' the components of the system behave as they do. Through a first-order cybernetic perspective, the 
patterns that underlie systemic structure are investigated, and the patterns of interactions are explored, which subsequently create rules and boundaries (Becvar \& Becver 2012). This theoretical perspective is valuable from a first-order perspective in understanding what components of sociopolitical space and geographical place influence schools' systemic boundaries. It is furthermore useful to establish and investigate boundaries and interactional feedback patterns within schools and community systems that underlie sexuality education within unique contexts.

However, Hoffman (1985) argued against the control exercised through acting as mere observer of a system and explaining interactional patterns without considering the role of the self within the system, and in turn the influence of the self as a stakeholder and researcher within the process as well. For this reason, the qualitative research investigation of this study will further be underpinned by the perspective of the researcher as a part of the systemic interaction and not merely an 'objective' observer (Heylighen \& Joslyn 2001), with reflexivity and feedback also being incorporated at systemic level of the narratives. The researcher will thus co-construct narratives with participants and will form an integral part in constructing data that are contextual to the realities of the participants' contexts and the manner in which the researcher, as both a participant in narrative construction and as an observer, understands and explains the 'what' and 'why' of sexuality education within specific settings. The use of both these theoretical underpinnings provides the researcher the opportunity to first, through a literature analysis, establish the core stakeholders and components of sexuality education in South Africa. A broad view can be gained about how the South African system is structured and what current feedback processes and disruptions to the systems have been found to influence sexuality education. While the aforementioned use of firstorder cybernetics can account for the system in such a way that the use of second-order cybernetics provides the researcher with the opportunity to become a part of the system, and thus be immersed into the context where semistructured interviews and conversation with participants become the focus. During this process, the researcher may gain a broad systemic view of sexuality education while also gaining a deeper, more contextualised, point of view.

\section{Methodology}

A qualitative paradigm was adopted as a means to understand the contextual underpinning of how schools manifest sexuality education. As the aim of this study was to gain a better understanding of how schools uniquely respond to and face boundaries regarding sexuality education, a qualitative approach proved valuable. It furthermore provides participants with an opportunity to reflect more deeply on their practices, while allowing for conversation and probing which sheds light on how sexuality education is located within a specific place and space, especially in relation to the cultural underpinning of space and place that is unique across the schools (Blanche, Durrheim \& Painter 2006). This narrative can then be discussed against the literature from a first-order systemic perspective as a means to better understand how contextual factors and larger national factors that may inhibit sexuality education interact and influence one another.

\section{Participants}

A total of 12 stakeholders within the primary context of education and schools were purposively sampled. Nonprobability sampling was utilised, and schools were specifically chosen on the contextual differences underlying them, as well as the culturally diverse places (Blanche et al. 2006). As such, schools were sampled and approached for gatekeeper consent (the principal being the primary gatekeeper), and permission was then granted to conduct research within the school at managerial level and teacher levels. While eight schools were initially approached as a means to provide an equal distribution between rural and urban schools, only six of the schools consented to participate. Participants are thus spread through the sampled schools. The total number of participants $(n=12)$ are thus spread across urban (8) and rural (4) schools. The demographics of the participants are as follows (see Table 1): eight were males and six were females, seven participants were Life Orientation teachers, while the remainder of the participants subsumed managerial roles within the school at various levels $(n=6)$.

\section{Data gathering and analysis}

Data gathering was done through semi-structured interviews with participants. Each interview lasted between 30 and $45 \mathrm{~min}$.

TABLE 1: Demographics of the study participants.

\begin{tabular}{|c|c|c|c|c|c|c|}
\hline Participant & School & School demographic & Role & Gender & Racial demographic & Age group (year) \\
\hline 1 & 1 & Urban & School Principal & Female & White person & $41-50$ \\
\hline 2 & 1 & Urban & Deputy Headmistress & Female & White person & $61-70$ \\
\hline 3 & 1 & Urban & Deputy Headmaster & Male & White person & $51-60$ \\
\hline 4 & 2 & Rural & Life Orientation and English Teacher & Male & Black person & $31-40$ \\
\hline 5 & 3 & Urban & Life Orientation Teacher & Female & White person & $21-30$ \\
\hline 6 & 1 & Urban & Life Orientation Teacher & Female & White person & $41-50$ \\
\hline 7 & 3 & Rural & Life Orientation Teacher & Male & Mixed race person & $41-50$ \\
\hline 8 & 4 & Rural & School Principal & Male & Black person & $51-60$ \\
\hline 9 & 5 & Rural & Life Orientation Teacher and Head of Department & Female & Black person & $41-50$ \\
\hline 10 & 1 & Urban & Life Orientation Teacher & Female & White person & $31-40$ \\
\hline 11 & 6 & Urban & School Principal & Male & White person & $51-60$ \\
\hline 12 & 6 & Urban & Life Orientation Teacher for 2 years & Male & White person & $51-60$ \\
\hline
\end{tabular}


The study primarily comprised individual interviews; however, because of time constraints, schools 1 and 6 requested a focus group interview. The researcher assisted in creating a dialogue within which the participants provided contextual information regarding their perceptions and experiences of sexuality education. Knowledge is, from a contextual and qualitative approach, a co-constructed concept. As such, the first-order cybernetics primarily informed the desktop review of literature and aspects within the results and discussion section through looking at the 'what' counterpart of systemic patterns. However, at a second-order cybernetic level, the researcher was active in the construction of knowledge, and as such stimulated the debate as a means to better understand the contexts the participants face in relation to sexuality education (Becvar \& Becvar 2012; Blanche etal.2006). There is thus a complimentary manner in which the researcher stimulates the information and probes from various sides, and the subsequent analysis to determine patterns and themes that emerge. This study was accordingly guided through Tesch's (1992) method of data analysis. Interviews were transcribed and similar patterns were identified and coded. Certain themes emerged from these codes, with this article specifically focusing on the theme of space, place and culture. While the data were viewed in their entirety at the end of data collection and transcription, it is important to note that the data analysis was already initiated during the interviews, providing the researcher with the opportunity to better stimulate contextual factors and patterns that emerged during the other interviews. What about the focus groups for schools 1 and 6 ?

\section{Ethical consideration}

This study was primarily registered with the host institution to perform research in the Free State schools. Gatekeeper consent and briefing were done, with the open acknowledgement that participation in the study is not mandatory and that participants could withdraw from the study at any time. No deception took place, and each participant was fully briefed about the scope and aims of the study. All narratives were coded and any references which may be indicative of the school were removed. The coded data are presented in the report through participant numbers, with no references alluding to the specific school on any level.

\section{Results and discussion}

The qualitative analysis of the data indicated that there is a strong thematic link which is established through participant narratives related to space, place and culture. The coding and thematic categorisation of the data established various aspects of subthemes related to space, place and culture as central themes explored in this article. These subcategories include the curriculum, religious boundaries and geographical contexts (see Table 2). The discussion of these categories will be based as one cohesive discussion, commencing with the curriculum boundaries established and moving towards broader geographical
TABLE 2: Themes extracted.

\begin{tabular}{lll}
\hline Main theme & Subthemes & Variable \\
\hline $\begin{array}{l}\text { Space and place within the } \\
\text { curriculum and beyond }\end{array}$ & Theme 1 & Curriculum \\
& Theme 2 & Religious boundaries \\
& Theme 3 & Geographical contexts \\
\hline
\end{tabular}

boundaries related to sexuality education. The themes will thus not be discussed under separate categories. This is indicative of the mutual role all of these factors play within schooling systems within one set of boundaries, as apart to being separate components working in isolation.

\section{Space and place within the curriculum and beyond}

Through the data analysis, it became clear from participant narratives that the space provided from the Curriculum and Assessment Policy Statement (CAPS) for Life Orientation bids either to closed or too open boundaries during the teaching of Life Orientation and its counterpart of sexuality education. Participant 4 illustrated the boundary of time and the curriculum as a closed boundary to optimal sexuality education in her school, as reflected through the below narrative:

If I look at the CAPS [Curriculum and Assessment Policies] curriculum and what is required and what is required time-wise for LO...what we do have, or the time that we do have is way less than what we are supposed to. Which makes it quite difficult to incorporate things like sexual and sexual orientation or education. Because you are only working with the books of course, so there is not really time. You have to incorporate everything into your schedule.

She then further elaborates on the manner in which this closed boundary leads to learner attitudes, further restricting the space within which sexuality education is taught:

'It's also very difficult when you are sitting with children who think that Life Orientation is a waste of time. So even though you are teaching important content, they don't necessarily feel it's important. What they take out of here, I don't always know if it is positive or if it is something that they deem as important for them to carry on with life.' (Participant 4 , male, rural school demographic)

Participant 5 (female, urban school demographic) also reflected on the limitations of the CAPS, as seen through the following narrative between them and the researcher:

Researcher: 'What is your opinion the way it (CAPS) explains and stipulates sex and sexuality that you have to teach?'

Participant 5: 'Okay...I think it is very superficial. You cover it... you do it a lot, instead of going deeper into the issues and what the learners are experiencing, for example, if they are gay...the judgment from others, how they exert themselves in their communities. Instead of talking about that, it is always about sex before marriage, STDs [sexually transmitted diseases], and that I have a problem with.'

Researcher: 'And is that specifically the CAPS, or would you say the textbooks as well?'

Participant 5: 'I think it is all round still, I don't think that CAPS and being teachers go deep into the subject matter.' 
Participant 5 reflects a narrative of critical reflection as to the limited space of content of the CAPS and the boundaries thereto within which teachers teach sexuality education. Her narrative reflects the manner in which the, often too open, space teachers have to interpret content can lead to open or closed boundaries depending on the teachers' perspectives of content relevance and personal choice. Research into sexuality education and its implementation within South African spaces has shown that emphasis is largely placed on the physical aspect of sexuality, thus placing importance on aspects such as HIV and AIDS, condom usage and abstinence versus safe sex practices. This emphasis deflects from the overall aim of holistic development in limiting the space within which sexuality education is mediated to not include aspects of sensuality, pleasure and the emotional underpinnings of relationships and sexual practices (Francis 2010).

The boundaries which mediate the type of sexuality education that teachers deliver, as deduced from the narrative extracts of participants, are twofold. Firstly, the personal backgrounds of teachers implicate the manner in which content is interpreted and presented, and secondly, the aspect of school place and location further plays a critical role therein. It is again evident from the following extracts and discussion that sexuality education in South Africa is highly entrenched in the sociopolitical climate, which is contextualitybased. What is important through the discussion hereof, especially from a cybernetic perspective, is the manner in which teachers are not solely responsible and accountable for what content is taught. The CAPS thus provides contextual space to accommodate the sociopolitical climates of different schools and takes into account the needs of different spaces and places depending on province and overall geographical location in accordance with other schools. There is thus a space within which the teacher can provide and interpret different messages to learners, depending on their own personal beliefs and experiences (Francis 2017), or ideally can tailor messages relevant to learners' backgrounds.

The teacher is merely one counterpart in a larger system, encompassing not only the curriculum, but he or she is also placed within a space where the larger suprasystem of place and culture comes into being, playing equally mediating roles. The role of culture and teacher background knowledge, for example, is drawn upon by participants 9 and 10. This lack of background knowledge often leads to misinformed teaching, causing teachers to draw on information which is not applicable to the needs of the learners (Swanepoel et al. 2017). This is seen through the following narratives:

'We work with different cultures at this school, like Sutu, Xhosa, Zulu, et cetera, coloured people, and I don't necessarily think the teacher that presents the class always understands the cultures when it comes to sexuality... Sometimes I feel we are trying to force down a Western culture on some of the children, and when they leave here they step into another world.' (Participant 10, female, urban school demographic)

'LO (Life Orientation) mainly, most of the teachers are old. So it becomes difficult for them to teach most of the things because they feel squirmish, others because of their cultural background they think they are too old to speak to children ... and if it is a graphic issue, sometimes it tends to be too graphic for them. And sometimes they do not have the background of psychology, so their approach is the main issue.' (Participant 9, female, school demographic)

In analysing the system within a 'what' first-order cybernetic perspective, the first level of the system, which dictates the space within which sexuality education is taught, accounts for the personal background of the educator, specifically religion:

Participant 10: ‘We discuss STDs, what would you do to prevent it, what behaviour ... so the behaviour is rather important, what will the risky behaviour, the main headings of the ...'

Researcher: ‘Would you advocate condom usage or abstinence?'

Participant 10: ‘For me, abstinence.'

Researcher: 'Why?'

Participant 10: 'For me, Christian beliefs. For me as a Christian it is often difficult to put my point across when I know there are others who do not have the same belief system that I have.'

While participant 10 takes on a very direct approach of abstinence because of Christian beliefs, participant 6 (female, urban school demographic) illustrates a more contextual approach that accommodates diversity of views and religion. This once again links with the manner in which the CAPS opens space for debate and critical conversation, or as in the previous participant's narrative, a space for the personal interpretation in how sexuality content is addressed at practical level within the classroom:

Researcher: 'And how do you bypass this personal bias? We all have a past. We all have experiences that have shaped our beliefs about homosexuality, about teenage pregnancies, abortion, sensitive issues. How do you bypass your own bias, your own religion that dictates certain things, and enter a classroom and then objectively start speaking about these sexual issues?'

Participant 6: 'It's probably the hardest thing, but you have to tell them from the start if they ask you what your opinion is, tell them this is my opinion, my beliefs, not to influence you in any way, and many times they would ask me "what is your opinion ma'm?" and I would say this is my beliefs. I'm a Christian and I believe this, and this, and this, and it's not judging what you believe and that's a big thing. They want to know that you do not judge them in how they think life should be or situation should be, or lifestyle should be.'

Participants 6 and 10 are situated within the same school; however, both reflect different manners of approaching sexuality education from the vantage point of their own backgrounds and culture. Probing further into how participant 10 teaches from the positioning of a perspective based on abstinence only, it becomes evident that the broader community and system are directly linked to the manner in which educators approach subjects during classroom practice, as well as the perception of educators as to their spatial movement and freedom to mediate content freely. Consider, for instance, the below narrative in which the educator reflects on spatial limitations to her approaching 
sexuality education to include community level boundaries, specifically the geographical context between urban and rural spaces, as well as parental level boundaries that mediate the space within which her content is positioned:

'For us it is definitely the environment the (learners) grow up in, you cannot compare the education we would do here to the education you would do in a township school. The (learners) here are informed. I think what also influences me is that $I^{\prime} m$ the parent of two teenagers and I know the issues and I understand how they see things, and then also, keeping in mind that if I as a parent would agree or like when my daughter comes home that this is what the teacher did discuss. A simple example, for instance, we had a discussion in the grade 10 class; there was a case study in the book about oral sex and after class two girls came to me and said they don't know what oral sex is, can I please explain it to them. And I was quite careful because I don't know if the parents would want them to know that yet. Although when I thought about it again, I was wondering if they really didn't know, and if they did that to get me to feel uncomfortable. It was a confusing situation. I don't know if your parents would be comfortable with their kids learning these things from someone else.' (Participant 6, female, urban school demographic)

The above narrative from participant 6 in an urban setting is confirmed by the narrative between participant 8 (male, rural school demographic) and the researcher, a school principal within a rural setting in the Free State province. The below narrative reflects how the positioning of sexuality education is specific to the setting where the school is located, thus creating specific contextual boundaries to the type of content and approach to teaching that is undertaken during Life Orientation:

Participant 8: 'Well it's a lot on reproduction, reproduction in terms of how we need to conduct ourselves, especially the learners ... the information that need to be disseminated, the safety in terms of what would be the repercussions if you indulge in unsafe sex. These are the things we focus on.'

Researcher: 'So is that what your Life Orientations focus on?'

Participant 8: 'Yes'

Researcher: 'So if I would ask you abstinence versus comprehensive sexuality education, would you lean more towards the abstinence counterpart?'

Participant 8: 'Yes, it plays a crucial role. But given the time and age we are living in now, it is so difficult to control it. Most of our learners are teenagers. They become sexually active at a very early age. I am not really sure whether it is because of the family backgrounds or what. Some of them are child-headed children and no parents.'

Participant 6 earlier referred to the informed nature of the learners within her class, stipulating that the education at the school where she teaches will differ from that in townships and rural settings. Through a second-order cybernetic perspective, and adopting a 'why' lens, I question whether learners in different settings are truly more or less informed in comparison, and whether the information and relevance thereof are rather different and contextually applicable. This once again indicates that knowledge is contextual, and that schools are contextually different in both place and space, thus forming different boundaries to sexuality education. However, all schools fall under the broader boundaries of the Free State and South Africa as a whole. This is clear from the narrative between participant 4 (male, rural school demographic) and the researcher, specifically stating that there are geographical boundaries to the teaching of sexuality education:

Participant 4: 'The community was having an influence on the school, based on my observation and experience. It was far east of the Free State. It is a rural place, it is one secondary and one primary. The learners, they are not exposed to maybe to... what is happening. So you realise that they are stuck to change. So the school tried to bring change, but they are resistant to that change.'

Researcher: 'Can you give me an example perhaps?'

Participant 4: 'Let me make a practical example. For example, in that place there is a culture amongst the black community, the initiation culture. And they will tell you that you must go there in order for you to be a man, and now these learners when they get to school, they don't want to accept the authority of teachers because culture has given them a view that they have the authority, they are men.'

Culture once again becomes evident as a strong mediator as to how sexuality education is introduced within the classroom. The above narrative had convinced me to further probe into how gender differences of teachers may cause limitations to sexuality education. Participant 9 (female, rural school demographic) articulated this to the researcher when asked about how the initiation culture influences her classroom practice. It is also important to note that a new stakeholder is introduced, namely, the community leader; this is a specific strategy employed by the school within a rural area. This lends validity to how different systems manifest and sustain sexuality education, and in turn that teachers are merely one of a myriad of stakeholders in the process. This was valuable in understanding how boys react to a female teacher teaching about sex and sexuality after they have undergone initiation, as well as their response to a female teacher:

Researcher: 'Have you had a specific situation that you can speak about how it implicated your classroom practice?'

Participant 9: 'In the other class I tried to introduce the issue and they just stood up and left. And then we had to talk to the community leader who is a male and then you invite them and talk to them and explain that this is in the curriculum, these are the things we need to talk about, they are not gender-based, they are more like trying to help the kids, it's a life skills things.'

Researcher: 'And how receptive were the community leaders about this, and how open were they to adjusting their values?'

Participant 9: 'It's how you approach them, like the one that we work with has an open mind, very flexible. I even invited him to one of the lessons as well and then I showed him what was in the book and, I am not trying to question what they are doing there. I am trying to give the learners the skills to be able to cope with all of the challenges facing them.'

From the above-mentioned narrative, it is noticeable that a multistakeholder approach is implemented in the process of sexuality education. The managerial aspect of opening the fluidity of boundaries between the school and the community becomes 
clear. This aligns with cybernetics in that new information can lead to systemic change, thus allowing for feedback that allows the system to adapt to expected standards. While participant 8 (male, rural school demographic) early indicated to the researcher that, as school principal, he advocates abstinence, this does not cause the school system to remain unchanged. The principal drew on external sources which proved valuable, allowing for positive feedback to occur within the school:

Participant 8: 'The main focus was on grade 8 , and the objective thereof was to try and demonstrate to the learners the difficulty of having a child. What they did was to provide them with cell phones and dolls. And this approach, I mean, it was for communication. Even at night, when they were at home, they called these learners to say feed the child. It was like a role play. When a child cries, what to do, such things. Feed the child; take the child to the doctor, the financial implications involved regarding raising the child.'

Researcher: 'In order to curb them from initiating sex, and then just at community level, how receptive has the community been because the school resides in a specific community and what you implement here would not always work in other schools? How did the community respond?'

Participant 8: 'It was positive because we started with the parents. We have to involve the parents. Actually, we invited all the parents who were going to be involved. We gave them the reasons as to the main purpose of the research and all the parents agreed and pledged their support for the programme. And I must confess in the beginning it yielded results, but since we stopped it ... it was on the side of the university ... the initiators, there is a very high level of pregnancy as we speak. On average here, per term, we have about five learners who fall pregnant. This is very high in my view. And I am talking about not only higher grades, from Grade 9 or even Grade 8 we do have those who are pregnant now.'

These narratives are indicative of the need to expand the space within which sexuality education takes place. It is therefore needed to not isolate the process to the classroom itself, but to involve stakeholders, such as parents and intuitions, in the process in order to allow for successful teachings to manifest. The dominant discourse of the teachers within rural areas emphasised the need to include the community and external sources. It is interesting to note from the following narrative that an urban school managerial team sustains the system internally, and that the school has a multi-stakeholder account of the dynamics within the school itself:

'The school governing body governs by means of approving policies. They govern by determining the curriculum and extracurricular activities offered by the school, so the school policy is the first way governing content, where you must understand that the senior management team, or first the executive team including myself and the two deputies, then communicate to the senior management team, and then we also have grade heads in place for different grades, because of the different developmental stages of the girls, and then we have the subject teachers, so, even though the governors determine an approve policy, the practical implementation happens on educator level.' (Participant 1 , female, urban school demographic)

Participant 10, a school principal within an urban context, also draws on the limitations of the teacher in teaching sexuality education. The participant reflects on broadening the space within which sexuality education is taught, encompassing community-based interventions to bridge the gaps of the teachers' limited knowledge:

'In classes ... I see in Life Orientation it does cause the educator ... The educators of Life Orientation cannot do that section, because of their personality and the way they feel about it, but what we've done before is you've got the groups together and you talk to them. The boys together and the girls together, separated. So you get people to come talk about that. I think the biggest drawback in class at this stage is the educator having to conduct that lesson on sexuality and that's where you get a roadblock, always, because you got a mixed class. (Participant 10 , female, urban school demographic)

I, however, question the approach undertaken by the school in separating boys and girls. The principal reflects on the limitations of the teacher in approaching a mixed class of boys and girls, and thus to intervene with programmes that create separate spaces where male and female learners are educated. This itself creates little space for learners to converse and learn about differences, and further dichotomises gender as only being male or female. I challenge this method of separation, in line with Francis (2017), in that schools are often places of gender categorisation, thus suggesting that gender diversity beyond the spectrum of male and female falls silent (Swanepoel \& Beyers 2015).

The contextual manner of different schools also becomes clear through the following narratives. While I have argued the difference in sexuality education between different schools, it becomes evident that the contextual space of the province also plays an important role. Consider, for example, how participants 9 and 10 reflect on the contextual differences related to provinces:

'I would feel that the national department would allow the provincial department to interact and involve the community leaders in the different provinces based on how they feel. Eastern Cape it is okay, we are allowed, we know we have the head man, the chief, if you have permission from that you can go ahead with everything. But here in the Free State it is a different story.' (Participant 9, female, rural school demographic)

'With the majority Sotho in the Free State, so the majority in the Free State. Western Cape is Xhosa and coloured people. So when you come to the Free State, you've got a Sotho dominant population and this will differ from other cultures, definitely.' (Participant 10, female, urban school demographic)

Participant 6 referred to her previous teaching experience, drawing on how the differences in contexts mediate her teachings. She compares the type of teachings in Johannesburg to her current context of the Free State:

'It's very open, liberal, accepted, rough, and out there, whereas here it's very narrow minded. It's like kids live in a box.' (Participant 6, female, urban school demographic)

From the above narratives and discussion, it becomes clear that the context of schools largely influences how sexuality education manifests and ultimately how the teacher responds to both the curriculum and learners. This context is shaped by 
the geographical underpinning of the school, which in turn reflects individual challenges, within the school and outside, specifically reminiscent of cybernetics and how the schools system is constantly responding to community-based input, as well as wider scale influences, such as the sociopolitical and historical influences from the province and the country as a whole. Each school, whether within the same province or same country, will be uniquely situated within a context that elicits different challenges with different systems responding thereto with different boundaries and reactions which either influence new information to enter the system or cause rejection thereof to retain systemic integrity.

\section{Conclusion}

The aim of this article was to investigate the question 'how do schools, from a systemic level, mediate sexuality education in relation to space, place and culture?' Through the use of firstand second-order cybernetics, it was found that place, space and culture are core themes that create boundaries for sexuality education. Within the themes of space, place and culture, there are various factors that further influence sexuality education, specifically the background knowledge and culture of teachers, religious underpinning of learners and teachers, and the contextual geographic of the place within which schools are located. Space and place are interrelated concepts, and thus sexuality education must be understood as a contextually based concept that is located within specific spaces. Such spaces are governed by South African benchmark expectations of social justice and inclusivity source. However, at practical level, it is not feasible to standardise the type of sexuality education that is taught. The study further found that sexuality education is not located solely within the Life Orientation classroom, but extends to the school system and beyond for a systemic multi-stakeholder space where stakeholders such as parents and the community become integral role players in attaining systemic stability and providing sexuality education that is contextually relevant while upholding democratic national policies and curricular expectations. This study reflects the necessity of contextuality-based research that supports the individual challenges of schools within the wider suprasystem of South Africa, with more researches needed to better understand how schools in different cities and provinces respond to challenges in unique ways. Furthermore, the need for educators to be aware of how their own background and context influence their classroom practice is also important, which calls on teachers and stakeholders to concisely interact in order to maintain open system boundaries that lead to positive change, as well as to identify the negative processes that the school system faces and realise the need to consider the broader system (community, city and provincial) factors that influence sexuality education at individual level.

\section{Acknowledgements Competing interests}

The authors declare that they have no financial or personal relationships that may have inappropriately influenced them in writing this article.

\section{Author's contributions}

E.S. contributed $51 \%$ of the article and C.B. contributed $49 \%$. Dr C. Beyers was the supervisor of E.S.

\section{References}

Ahmed, N., Flisher, A.J., Mathews, C., Mukoma, W. \& Jansen, S., 2009, 'HIV education in South African schools: The dilemma and conflicts of educators', Scandinavian Journal of Public Health 37(2 Suppl.), 48-54. https://doi.org/10.1177/140349480 8097190

Banathy, B.H. \& Jenlink, P.M., 2003, 'Systems inquiry and its application in education', in D.H.E. Jonassen (ed.), Handbook of research for educational communications and technology, 2nd edn., pp. 37-58, Lawrence Erlbaum Associates, Mahwah, NJ.

Becvar, D.S. \& Becvar, R.J., 2012, Family therapy: A systemic integration, Pearson Higher Ed., Cape Town.

Beyers, C., 2013, 'In search of healthy sexuality: The gap between what youth want and what teachers think they need', The Journal for Transdisciplinary Research in Southern Africa 9(3), 550-560. https://doi.org/10.4102/td.v9i3.197

Blanche, M.J.T., Durrheim, K. \& Painter, D. (eds.), 2006, Research in practice: Applied methods for the social sciences, UCT Press, Cape Town.

Carrera, M.V., DePalma, R. \& Lameiras, M., 2012, 'Sex/gender identity: Moving beyond fixed and "natural" categories', Sexualities 15(8), 995-1016. https://doi.org/ $10.1177 / 1363460712459158$

Cobbett-Ondiek, M., 2016, 'Peering into "spaces for change": Empowerment, subversion and resistance in a gendered violence prevention education programme in Kenya', Sex Education 16(6), 663-677. https://doi.org/10.1080/14681811.2016. 1165658

DePalma, R. \& Francis, D., 2014, 'Silence, nostalgia, violence, poverty...: What does "culture" mean for South African sexuality educators?', Culture, Health \& Sexuality 16(5), 547-561. https://doi.org/10.1080/13691058.2014.891050

DePalma, R. \& Jennett, M., 2010, 'Homophobia, transphobia and culture: Deconstructing heteronormativity in English primary schools', Intercultural Education 21(1), 15-26. https://doi.org/10.1080/14675980903491858

Department of Basic Education, 2011, Curriculum and assessment policy statement grades 7-9: Life orientation, Government Printing Work, Pretoria, South Africa.

Fields, J. \& Payne, E., 2016, 'Editorial introduction: Gender and sexuality taking up space in schooling', Sex Education 16(1), 1-7.

Francis, D., 2016, "I felt confused; I felt uncomfortable ... my hair stood on ends": Understanding how teachers negotiate comfort zones, learning edges and triggers in the teaching of sexuality education in South Africa', in V. Sundaram \& $\mathrm{H}$. Sauntson
(eds.), Global perspectives and key debates in sex and relationships education: Addressing issues of gender, sexuality, plurality and power, pp. 130-145, Palgrave Macmillan, London.

Francis, D.A., 2010, 'Sexuality education in South Africa: Three essential questions', International Journal of Educational Development 30(3), 314-319. https://doi. org/10.1016/j.ijedudev.2009.12.003

Francis, D.A., 72017, Troubling the teaching and learning of gender and sexuality diversity in South African education, Springer.

Haberland, N. \& Rogow, D., 2015, 'Sexuality education: Emerging trends in evidence and practice', Journal of Adolescent Health 56(1), S15-S21. https://doi.org/ 10.1016/j.jadohealth.2014.08.013

Heylighen, F. \& Joslyn, C., 2001, 'Cybernetics and second order cybernetics', Encyclopedia of PST Physical Science \& Technology 4, 155-170.

Hoffman, L, 1985, 'Beyond power and control: Toward a "second order" family systems therapy', Family Systems Medicine 3(4), 381. https://doi.org/10.1037/ h0089674

Jonck, P. \& Swanepoel, E., 2015, 'Exploring the theoretical link between cultural and emotional intelligence: A system analysis for human resource management' South African Journal of Business Management 46(4), 77-84. https://doi.org/ 10.4102/sajbm.v46i4.111

Msibi, T., 2012, “'I'm used to it now”: Experiences of homophobia among queer youth in South African township schools', Gender and Education 24(5), 515-533. https:// doi.org/10.1080/09540253.2011.645021

Mthatyana, A. \& Vincent, L., 2015, 'Multiple femininities in a "single sex" school: Re-orienting life orientation to learner lifeworlds', Perspectives in Education 33(2), 49-62.

Reygan, F. \& Francis, D., 2015, 'Emotions and pedagogies of discomfort: Teachers' responses to sexual and gender diversity in the Free State, South Africa', Education as Change 19(1), 101-119. https://doi.org/10.1080/16823206.2014. Education
943259

Shefer, T. \& Ngabaza, S., 2015, "'And I have been told that there is nothing fun about having sex while you are still in high school": Dominant discourses on women's sexual practices and desires in life orientation programmes at school', Perspectives in Education 33(2), 63-76.
s.

Swanepoel, E. \& Beyers, C. 2015, 'From personal sexuality bias to the life orientation classroom: Bridging the gap with cultural intelligence', Journal of Psychology in Africa 25(2), 164-169. https://doi.org/10.1080/14330237.2015. 1021535 
Swanepoel, E.H., Beyers, C. \& De Wet, L., 2017, 'Exploring judgement and internal bias of life orientation teachers in sexuality teaching', The Journal for Transdisciplinary Research in Southern Africa 13(1), a405. https://doi.org/ 10.4102/td.v13i1.405

Tesch, R., 1992, Qualitative research: Analysis types and software tools, Falmer Press, Hampshire.

The Bill of Rights of the Constitution of the Republic of South African, 1996, Government Gazette. (No. 17678).
Vavrus, M., 2009, 'Sexuality, schooling, and teacher identity formation: A critical pedagogy for teacher education', Teaching and Teacher Education 25(3), 383-390. https://doi.org/10.1016/j.tate.2008.09.002

Weeks, F.H., 2012, 'The quest for a culture of learning: A South African schools perspective', South African Journal of Education 32(1), 1-14. https://doi. org/10.15700/saje.v32n1a565

Woolley, S.W., 2017, 'Contesting silence, claiming space: Gender and sexuality in the neo-liberal public high school', Gender and Education 29(1), 84-99. https://doi. org/10.1080/09540253.2016.1197384 